\title{
Rotatory knee laxity and the pivot shift
}

\author{
Volker Musahl • Yuichi Hoshino • Roland Becker • \\ Jon Karlsson
}

Received: 6 December 2011 / Accepted: 13 December 2011/Published online: 24 December 2011

(c) Springer-Verlag 2011

Ejnar Eriksson, in a KSSTA editorial almost 10 years ago, wrote, "I do not think that we yet know enough about how to reconstruct the ACL ideally" [2]. He suggested we should continue with our research efforts. We did. In the following 10 years, the research data in terms of ACL research have more than doubled (Medline search). Rotatory knee laxity is a particularly interesting topic and remains frequently researched. Yet, it is vexing to us that although we have such passion for ACL research, we still don't fully understand the factors that guarantee adequate restoration of rotatory knee laxity following an ACL injury.

Bull et al. [1] described this phenomenon as "envelope of motion" and used the pivot shift to illustrate that ACLdeficient knees followed the same general path of motion during subluxation and reduction, but that no two knees moved in the same manner. An interesting and still unresolved question is whether we pre-operatively can define and-more difficult-surgically restore knees that display markedly increased rotation?

\footnotetext{
V. Musahl $(\bowtie)$

Department of Orthopaedic Surgery, Center for Sports Medicine, University of Pittsburgh, 3200 S Water Street,

Pittsburgh, PA 15203, USA

e-mail:musahlv@upmc.edu

Y. Hoshino

Department of Orthopaedic Surgery, Kobe University,

Kobe, Japan

R. Becker

Department of Orthopaedic and Traumatology,

City Hospital Brandenburg,

Brandenburg, Germany

J. Karlsson

Department of Orthopaedics, Sahlgrenska University Hospital,

Göteborg, Sweden
}

This special issue "Rotatory Knee Laxity and the Pivot Shift" features a large number of original and review articles from clinician and scientist experts in the field. Articles also cover experiments from the Panther Global Summit (Pittsburgh, August 2011). Additionally, we asked the contributing authors to strictly adhere to a common terminology, specifically with respect to the terms, "laxity" and "instability", which are often confused. We hope this will make the articles easier to read and follow, more understandable and enjoyable.

We distinctly remember a session on rotatory knee laxity during the 2006 ACL Study Group meeting in Hawaii. There were several topics on rotatory laxity and rotatory instability. So, what is the difference? During this session, John Feagin defined these terms for the audience "instability is a symptom described by a patient, whereas laxity is an objective finding" [3]. In biomechanical terms, laxity is the passive response of a joint to an externally applied force or torque. Stability, on the other hand, is a functional measure; that is, a knee, regardless of laxity, is only unstable if it "gives way" during functional activities. Therefore, laxity does not imply instability, since a lax joint could be stabilized via neuromuscular control [7].

The pivot-shift test is a particularly complicated, yet highly specific test for ACL deficiency. Only when the ACL is deficient can the lateral tibial plateau sublux anteriorly. It is therefore a test for ligamentous laxity, or isn't it? Well, during the reduction of the pivot-shift test when the lateral tibial plateau translates posteriorly, the examiner can feel a sudden shift, and the patient will verbalize concern of instability ("giving way") [4]. We are actually testing rotational instability. So, where does this test really fit in? Some researchers view the pivot-shift test as a "bridge" between simple static biomechanic tests (e.g., cadaveric, robotic, simulated) and functional dynamic 
kinematic tests (e.g., video motion analysis and dynamic stereo radiography). Some of the answers can be found in this special issue of KSSTA.

The pivot-shift testing procedure is also complicated because we all appear to have a different interpretation on how to apply and interpret the test. In a way, it would make sense to "standardize" the pivot shift, so that clinical outcome can be compared in a meaningful manner. During the Panther Global Summit (Pittsburgh, August 2011), we conducted a study with 12 expert surgeons. We found that after watching an instructional video, explaining a standardized pivot-shift technique, their pivot-shift examinations not only looked similar but displayed similar acceleration curves, whereas during the surgeons' preferred technique, they did not.

We are confident that the instructional video will stimulate discussion and will be helpful in designing research projects. The video is available on the KSSTA website.

The goal of an ACL reconstruction should be to reduce the pivot shift! Defining and quantifying the pivot shift pre-operatively is done during the examination under anesthesia (EUA). A high-grade pivot shift may indicate combined injury to the ACL and secondary restraints, small coronal diameter of the lateral tibial plateau [6], or generalized ligamentous laxity [5]. However, to answer the question above, knees that display high-grade pivot shifts, or have excess knee rotational laxity, cannot always be identified pre-operatively. It is the goal of this special issue of KSSTA to answer some of these questions, stimulate further research questions, and more clearly define the role of the pivot shift. The ultimate goal is to standardize the pivot shift.

\section{References}

1. Bull AM, Earnshaw PH, Smith A, Katchburian MV, Hassan AN, Amis AA (2002) Intraoperative measurement of knee kinematics in reconstruction of the anterior cruciate ligament. J Bone Joint Surg Br 84(7):1075-1081

2. Eriksson E (2003) Does ACL reconstruction restore normal tibial rotation? Knee Surg Sports Traumatol Arthrosc 11(6):359

3. Feagin J (2006) Personal communication. ACL study group, Hawaii

4. Galway HR, MacIntosh DL (1980) The lateral pivot shift: a symptom and sign of anterior cruciate ligament insufficiency. Clin Orthop Relat Res 147:45-50

5. Kim SJ, Chang JH, Kim TW, Jo SB, Oh KS (2009) Anterior cruciate ligament reconstruction with use of a single or doublebundle technique in patients with generalized ligamentous laxity. J Bone Joint Surg Am 91(2):257-262

6. Musahl V, Ayeni OR, Citak M, Irrgang JJ, Pearle AD, Wickiewicz TL (2010) The influence of bony morphology on the magnitude of the pivot shift. Knee Surg Sports Traumatol Arthrosc 18(9): $1232-1238$

7. Snyder-Mackler L, Fitzgerald GK, Bartolozzi AR III, Ciccotti MG (1997) The relationship between passive joint laxity and functional outcome after anterior cruciate ligament injury. Am J Sports Med 25(2):191-195 